\title{
Modeling Non-Steady State Radioisotope Transport in the Vadose Zone - A Case Study Using Uranium Isotopes at Peña Blanca, Mexico
}

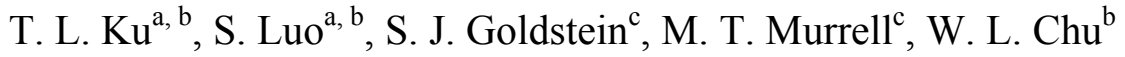 \\ and P. F. Dobson ${ }^{\mathrm{d}}$ \\ ${ }^{a}$ Department of Earth Sciences, University of Southern California, Los Angeles, CA 90089, USA \\ ${ }^{\mathrm{b}}$ Department of Earth Sciences, National Cheng Kung University, Tainan 701, Taiwan, ROC \\ ${ }^{\mathrm{c}}$ Nuclear and Radiochemistry Group, Los Alamos National Laboratory, \\ P.O. Box 1663, MS J514, Los Alamos, New Mexico 87545, USA \\ ${ }^{d}$ Earth Sciences Division, Lawrence Berkeley National Laboratory, Berkeley, CA 94720, USA
}

\begin{abstract}
Current models using U- and Th-series disequilibria to study radioisotope transport in groundwater systems mostly consider a steady-state situation. These models have limited applicability to the vadose zone (UZ) where the concentration and migratory behavior of radioisotopes in fluid are often transitory. We present here, as a first attempt of its kind, a model simulating the non-steady state, intermittent fluid transport in vadose layers. It provides quantitative constraints on in-situ migration of dissolved and colloidal radioisotopes in terms of retardation factor and rock-water interaction (or water transit) time. For uranium, the simulation predicts that intermittent flushing in the UZ leads to a linear relationship between reciprocal $U$ concentration and ${ }^{234} \mathrm{U} /{ }^{238} \mathrm{U}$ ratio in percolating waters, with the intercept and slope bearing information on the rates of dissolution and $\alpha$-recoil of $U$ isotopes, respectively. The general validity of the model appears to be borne out by the measurement of uranium isotopes in $\mathrm{UZ}$ waters collected at various times over a period during 1995-2006 from a site in the Peña Blanca mining district, Mexico, where the Nopal I uranium deposit is located. Enhanced ${ }^{234} \mathrm{U} /{ }^{238} \mathrm{U}$ ratios in vadose-zone waters resulting from lengthened non-flushing time as prescribed by the model provide an interpretative basis for using ${ }^{234} \mathrm{U} /{ }^{238} \mathrm{U}$ in cave calcites to reconstruct the regional changes in hydrology and climate. We also provide a theoretical account of the model's potential applications using radium isotopes.
\end{abstract}

Key words: radioisotope transport, vadose zone, modeling, non-steady state, uranium isotopes, Peña Blanca 


\section{INTRODUCTION}

The distribution and mobility of radioisotopes in the vadose zone are far less understood than that in the phreatic or saturated zone. Among the contributing factors to this knowledge gap is the lack of attempts at modeling radioisotope migration in unsaturated media. The present study represents such an attempt based on the observational data on uranium isotopes obtained from Peña Blanca, Mexico.

The Nopal I deposit at Peña Blanca, a uranium mining district located approximately $50 \mathrm{~km}$ north of Chihuahua City, Mexico (Fig. 1), bears certain similarities to the proposed high-level radioactive waste repository at Yucca Mountain, Nevada (Goodell, 1985; Murphy, 1995). The similarities lie in terms of climatic (arid to semiarid), hydrologic ( $>100-\mathrm{m}$ unsaturated and oxidizing zones) and geologic (basin-and-range horst structure composed of fractured Tertiary rhyolitic tuffs overlying carbonate aquifers) settings. In addition, the paragenesis of uranium mineralization observed at Peña Blanca has some similarity to alteration products of spent nuclear fuel (Leslie et al., 1993; Murphy, 2000). These similar characteristics have prompted studies of the site as a natural analogue for evaluating radionuclide transport processes that may be relevant to the proposed Yucca Mountain repository (e.g., Pearcy et al., 1994; Murphy and Pearcy, 1993). One such evaluation would be the quantitative assessment of radionuclide mobility on a range of time scales, which can be made using the parent-daughter disequilibrium relationships of naturally occurring decay-series nuclides observed in subsurface environments at this analogue site.

Models of rock-water interactions utilizing the U- and Th-series disequilibria in fluids to assess radioisotope migration commonly invoke a steady-state assumption (e.g., Ku et al., 1992; Trica et al., 2001; Porcelli, 2008). While capable of elucidating the mobility of radioisotopes in the phreatic zone, these models may not suffice to constrain isotope transport in the vadose zone where non-steady conditions often prevail. In order to gain new insights as to the nature of transport of radionuclides in unsaturated media, we have repeatedly sampled seepage water within the vadose zone at Peña Blanca and the sampling was followed by measurements of ${ }^{238} \mathrm{U}$ and ${ }^{234} \mathrm{U}$. The measurements, together with some data published earlier for the site, provide us a first comprehensive dataset on uranium isotopes in unsaturated water-rock systems. It forms the basis for our effort here in extending the transport models discussed by Ku et al. (1992) to include non-steady-state situations 
A certain feature of uranium isotope behavior in the vadose zone, namely, seasonal distributions of ratio ${ }^{234} \mathrm{U} /{ }^{238} \mathrm{U}$ in the seepage water, is captured by the non-steady state model. As variations of ${ }^{234} \mathrm{U} /{ }^{238} \mathrm{U}$ have been found in cave-calcite deposits (e.g., Kaufman et al., 1998; Hellstrom and McCulloch, 2000), our study may also bear implications on the potential use of ${ }^{234} \mathrm{U} /{ }^{238} \mathrm{U}$ in cave calcites as a proxy for reconstructing past changes in regional hydrology and climate.

\section{MODEL DESCRIPTION}

Fluid-based models of rock-water interactions generally envision that radionuclides in natural water-rock systems reside in three pools: solid (rock minerals/particles), sorbed (rock/fracture surfaces), and dissolved (interstitial water) (Ku et al., 1992). In some cases (see, e.g., Porcelli and Swarzenski, 2003), one may further add colloidal particles as a fourth pool and to a first approximation treat it as a mobile particle pool (Ku et al., 1998). As schematically shown in Fig. 2, nuclides in the dissolved pool are assumed to exchange reversibly and rapidly with those in the sorbed pool residing on surfaces and with those in the colloidal pool. The exchange is rapid and complete such that a constant ratio of radionuclide concentration exists between the dissolved and sorbed/colloidal pools - as defined by the distribution coefficient, $K_{d}$. In contrast, nuclides in the dissolved pool have very limited communication with those in the solid pool located further inside the rock. Transfer of radionuclides between the dissolved and solid pools is assumed to take place through the processes of dissolution, precipitation and $\alpha$-recoil. Radionuclides in the solid pool are transferred to the dissolved pool through dissolution and $\alpha$-recoil, whereas those in the dissolved pool are incorporated into the solid pool through precipitation. The rates of dissolution and precipitation are kinetically controlled by rock weathering processes. Under these assumptions, the following equation can be written to describe the time rate of change of concentration, $C^{*}(x, t)$, of a radionuclide with decay constant $\lambda$ in a parcel of water moving through the water-rock system (See Appendix 1 for derivation):

$$
\frac{d C^{*}}{d t}=P-\lambda R_{f}^{*} C^{*}
$$

where $C^{*}=C+C_{\mathrm{c}} ; C$ and $C_{\mathrm{c}}$ are respectively concentrations in dissolved and colloidal pools; $P$ is the supply rate of the radionuclide through dissolution, $\alpha$ recoil, and in-situ radioactive decay (Krishnaswami, 1982; Ku et al., 1992); and $R_{f}^{*}$ is a parameter called the effective retardation factor, 
which gives a measure of the radionuclide's mobility relative to the fluid mobility owing to sorption, precipitation and colloidal association; namely, $R_{f}^{*}=1+C_{a} / C^{*}+k_{p} / \lambda$, where $C_{a}$ is concentration in the sorbed pool, $k_{p}$ is the first-order precipitation rate constant and $\lambda$ is the decay constant of the radionuclide (Ku et al., 1992; 1998). It is related to the customarily used retardation factor $R_{f}$, which takes into account only sorption/desorption (i.e., $R_{f}=1+K ; K$ is the dimensionless distribution coefficient; see Krishnaswami et al., 1982), via the relationship

$$
R_{f}^{*}=\left(R_{f}+\frac{k_{p}}{\lambda}\right)-f_{c}\left(R_{f}+\frac{k_{p}}{\lambda}-1\right)
$$

where $f_{\mathrm{c}}$ is the ratio $C_{\mathrm{c}} /\left(C+C_{\mathrm{c}}\right)$. Owing to the fact that $R_{f} \geq 1$ and $k_{p}>0$, the last term in this equation has a negative value and depicts the reduction of retardation by colloidal association. Colloid formation can greatly reduce the retardation of thorium, for example (Contardi et al., 2001).

Equation (1) serves as the basic formula for a general non-steady state model that uses the distribution of naturally occurring $\mathrm{U}$ - and Th-series isotopes to constrain nuclide transport in waterrock systems. By "general", we mean that the model is in principle applicable to radioisotopes in unsaturated as well as saturated zones of a water-rock system; it provides simultaneous constraints on the behavior of radioisotopes in dissolved (-colloidal), adsorbed, and solid pools of these systems.

Applying the model to a system with initial condition (i.e., prior to rock-water interaction) $C_{t=0}^{*}$ $=0$ gives

$$
A^{*}=\frac{P}{R_{f}^{*}}\left(1-e^{-\lambda R_{f}^{*} \tau_{w}}\right)
$$

Here, $A^{*}\left(=\lambda C^{*}\right)$ is nuclide activity and $\tau_{w}$ is the effective water-rock interaction (or transit) time, which in the vadose zone, because of its unsaturated nature, may differ from the actual water transit time. Their ratio, $A^{*} / \tau_{w}$, gives a measure of the radionuclide mobility in terms of rates of supply and transport. It can be seen that for a conservative radionuclide $\left(R_{f}^{*}=1\right.$, as $R_{f}=1$ and $\left.k_{p}=0\right)$ with supply rate $P$, its mobility is governed by the water transit time. For a non-conservative radionuclide, its supply rate to groundwater of $P / R_{f}^{*}$ is seen to be effectively attenuated by a factor of $R_{f}^{*}$. For a onedimensional flow with water advection velocity $V_{w}, \tau_{w}=x / V_{w}$ and Eq. (3) can be written as 
$A^{*}=\left(P / R_{f}^{*}\right)\left(1-e^{-\lambda x / V_{w}^{*}}\right)$, depicting that the effective transport velocity $\left(V_{w}^{*}=V_{w} / R_{f}^{*}\right)$ of the radionuclide will also be smaller than the water advection velocity $\left(V_{w}\right)$ by a factor of $R_{f}^{*}$.

There can be value in using Eq. (3) to aid in assessing the potential for mobilization and transport of radionuclides within the unsaturated zone. The rates by which radionuclides move to the saturated zone (SZ) depend largely on groundwater migration rates $\left(V_{w}\right)$ and radionuclide retardation factors $\left(R_{f}^{*}\right)$. Evaluation of these parameters can be made from the measurement of naturally occurring decay-series isotopes. Below we show the application of the model and its validation using data on uranium isotopes obtained from waters collected from the Peña Blanca site. We will also discuss the model's potential for assessing the UZ transport of Ra and Th isotopes.

\section{MODELING U-ISOTOPE TRANSPORT IN THE UNSATURATED ZONE (UZ)}

\subsection{Linear ${ }^{234} \mathrm{U} /{ }^{238} \mathrm{U}$ vs. $1{ }^{238} \mathrm{U}$ relationship and its implications}

Applying the model to ${ }^{238} \mathrm{U}$ by assuming that $k_{\mathrm{p}}<<1 / \tau_{w}$ (considering the short residence time of water in the vadose zone in general), we see that $\lambda R_{f}^{*} \tau_{w}<<1$ (due to the very small decay constant of ${ }^{238} \mathrm{U}$; i.e., $\lambda=1.55 \times 10^{-10} \mathrm{y}^{-1}$ ), and Eq. (3) can be simplified to

$$
A_{238 U}^{*}=\lambda_{238 U} \tau_{w} P_{d, 238 U}
$$

This relationship suggests that the concentration of ${ }^{238} \mathrm{U}$ in water passing through the $\mathrm{UZ}$ is determined by the effective water-rock interaction time $\left(\tau_{w}\right)$ and dissolution rate of ${ }^{238} \mathrm{U}\left(P_{d, 238 U}\right)$ from solids. In applying this relationship to ${ }^{234} \mathrm{U}$, we further consider the $\alpha$-recoil input $\left(P_{r}\right)$ of ${ }^{234} \mathrm{U}$ from rock/fracture surfaces. Unlike dissolution which occurs upon the intermittent flushing of water (an assumption is made here that dissolution by vapor during the non-flushing period is of minor importance) through the UZ, $\alpha$-recoil occurs with or without the passing water. The process of $\alpha$ recoil during ${ }^{238} \mathrm{U}$ decay produces enrichment of short-lived ${ }^{234} \mathrm{Th}$, hence ${ }^{234} \mathrm{U}$, near/at a solid surface (see e.g., Gascoyne, 1982). The recoil-produced ${ }^{234} \mathrm{U}$ located near/at surfaces during a non-flushing period is later released into water when flushing takes place in the UZ. This intermittent flushing phenomenon is characteristic of the vadose zone. Taking $\tau_{o}$ as the effective non-flushing time, we modify Eq. (4) for ${ }^{234} \mathrm{U}$ as follows: 


$$
A_{234 U}^{*}=\lambda_{234 U} \tau_{o} P_{r, 234 U}+\lambda_{234 U} \tau_{w}\left(P_{r, 234 U}+P_{d, 234 U}\right)
$$

Different water parcels in the vadose zone may take different transport pathways (especially in a fractured medium) and have different water-rock interaction times $\left(\tau_{w}\right)$, hence among the four parameters $\left(\tau_{o}, \tau_{w}, P_{r}\right.$, and $\left.P_{d}\right)$, only three $\left(\tau_{o}, P_{r}\right.$, and $\left.P_{d}\right)$ may be assumed constant and be constrained by Eqs. (4) and (5). Combining the two equations to eliminate $\tau_{w}$ gives a linear relationship in the plot of $A_{234 U}^{*} / A_{238 U}^{*}$ vs. $\left(A_{238 U}^{*}\right)^{-1}$ :

$$
\frac{A_{234 U}^{*}}{A_{238 U}^{*}}=\frac{m}{A_{238 U}^{*}}+b
$$

with slope $m=\lambda_{234 U} \tau_{o} P_{r, 234 U}$, and $y$-intercept $b=\left(\lambda_{234 U} P_{r, 234 U} / \lambda_{238 U} P_{d, 238 U}\right)+1$. The model predicts that for a given set of $\tau_{o}, P_{r}$ and $P_{d}$, the measured activity ratio ${ }^{234} \mathrm{U} /{ }^{238} \mathrm{U}$ is inversely related to ${ }^{238} \mathrm{U}$ activities in water percolating through the UZ.

Measurements of uranium isotopes made by Pickett and Murphy (1999) on waters near the Nopal I uranium deposit located around $29^{\circ} 07^{\prime} \mathrm{N}$ and $106^{\circ} 02^{\prime} \mathrm{W}$ provide a database for an initial test of the model. Indeed, these workers were the first to note from their measurements that a positive linear correlation exists between ${ }^{234} \mathrm{U}^{238} \mathrm{U}$ and reciprocal $\mathrm{U}$ concentration for waters originated from the UZ. They cast the correlation in terms of rock-water interaction, but made no attempt at a quantitative analysis of the linearity.

Pickett and Murphy (1999) analyzed ${ }^{234} U$ and ${ }^{238} U$ in five filtered water samples collected in August-September 1995: two seep waters that had traversed at least $8 \mathrm{~m}$ of rock from the ground surface and entered a mine adit constructed on Level +00 near the PB1 well (Fig. 1), two perched water samples trapped in an old borehole on Level +10 exposure, and groundwater from well PB4 in a limestone aquifer of Cretaceous age $\sim 1.3 \mathrm{~km}$ southeast of the deposit (Fig. 1). The UZ rocks above the mine adit are composed of welded tuffs that host the uranium deposit. According to these investigators, none of the collected UZ waters had traversed the zone of visible uranium mineralization, as much of the adit has no $\mathrm{U}$ ore above it. They reported uranium concentrations of

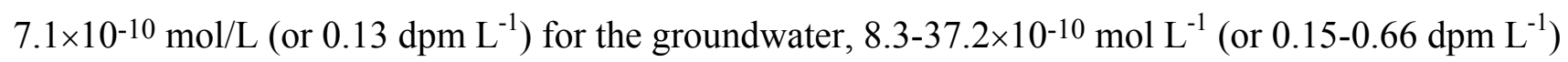
for the seep water, and 2.0-2.4 $\times 10^{-8} \mathrm{~mol} \mathrm{~L}^{-1}$ (or 3.6-4.3 $\mathrm{dpm} \mathrm{L}^{-1}$ ) for the perched water. Figure $3 \mathrm{a}$ shows a plot of their uranium isotope data. 
A linear correlation is clearly seen between ${ }^{234} \mathrm{U} / 238 \mathrm{U}$ and $1 / 238 \mathrm{U}$ in vadose-zone waters as predicted by Eq. (6). That the one data point for the sample from the limestone aquifer (saturated zone) falls way off the linear trend is not unexpected; it serves to give a measure for the sensitivity of the modeling. Its much lower ${ }^{234} \mathrm{U} / 238 \mathrm{U}$ may well reflect a prolonged interaction of the aquifer water with old calcites that contain $\mathrm{U}$ isotopes in secular equilibrium, allowing $\mathrm{U}$ exchange between rock and solution to mask the effect of $\alpha$-recoil-induced ${ }^{234} \mathrm{U}$ enrichment in the water.

The Eq. (6) relationship offers a means to constrain the input rates of uranium from solids to the solution through dissolution and $\alpha$-recoil. As seen in Fig. (3a), the linear fit has a slope $m=$ $0.45 \pm 0.01 \mathrm{dpm} \mathrm{L}^{-1}$ and an intercept $b=2.1 \pm 0.2$, from which one can derive $P_{r}$ and $P_{d}$. For illustration purposes, let us assume an effective non-flushing time $\tau_{o} \approx 0.05 \mathrm{y}$ for water samples collected during September 1995. This assumed value is similar in magnitude to the 1961-1972 average monthly rainfall data from the Los Pozos weather station of Mexican National Meteorological Service. We estimate from the slope a recoil rate for ${ }^{234} \mathrm{U}\left(\lambda P_{r}\right)$ of $\sim 9 \mathrm{dpm} \mathrm{L}^{-1} \mathrm{y}^{-1}$. The dissolution rates, estimated from the $y$ intercept of 2.1, would be $\sim 8.3 \mathrm{dpm} \mathrm{L}^{-1} \mathrm{y}^{-1}$ for both ${ }^{238} \mathrm{U}$ and ${ }^{234} \mathrm{U}$ (or $\sim 47 \times 10^{-9} \mathrm{~mol} \mathrm{~L}^{-1} \mathrm{y}^{-1}$ for ${ }^{238} \mathrm{U}$ and $\sim 2.6 \times 10^{-12} \mathrm{~mol} \mathrm{~L}^{-1} \mathrm{y}^{-1}$ for $\left.{ }^{234} \mathrm{U}\right)$.

The model also allows estimation of the fluid-rock interaction time $\left(\tau_{w}\right)$ in the UZ. Equation (4) indicates that given a constant $P_{d}$ (as expected from a relatively short transit time of water in the UZ), ${ }^{238} \mathrm{U}$ concentrations increase linearly with increasing $\tau_{w}$ as illustrated in Fig. $3 \mathrm{~b}$ for the above-derived $P_{d}$ of $\sim 8.3 \mathrm{dpm} \mathrm{L}^{-1} \mathrm{y}^{-1}$. In contrast, Eq. (6) predicts that the ${ }^{234} \mathrm{U} / 238 \mathrm{U}$ ratio initially decrease rapidly with increasing $\tau_{w}$ and then reaches a near-constant level dictated by the $P_{r} / P_{d}$ ratio. This is shown in Fig. 3b, again using the data of Pickett and Murphy (1999), by taking a $P_{r} / P_{d}$ ratio of $1.1(=9 / 8.3)$ for the $\mathrm{UZ}$ and a $P_{r} / P_{d}$ ratio of 0.4 for the saturated zone (i.e., for a ${ }^{234} \mathrm{U} /{ }^{238} \mathrm{U}$ activity ratio of 2.1 in seepage water and of 1.39 in the carbonate aquifer). Our model suggests that high ${ }^{234} \mathrm{U} / 238 \mathrm{U}$ ratios could occur in $\mathrm{UZ}$ water that has experienced a relatively short effective transit time $\left(\tau_{w}\right)$. It is estimated that at the Nopal I site near well PB1 around 1995, effective transit time $\tau_{w}\left(=[\mathrm{U}] / P_{d}\right)$ for the seepage water to percolate from the Level +10 ground surface into the Level +00 adit $\geq 8 \mathrm{~m}$ below was about 6-29 days, and that for the perched water bailed from uncased borehole at $10.7 \mathrm{~m}$ depth, it was about $0.4-0.5$ years. The large values of $\tau_{w}$ for the perched water may reflect the long residence time of water in the borehole. The large difference in $\tau_{w}$ between the perched and seep waters also suggests the existence of different pathways, with little connectivity and affected possibly by fracture 
flow. In a low water-flux and relatively high U-concentration setting near the Nopal I uranium deposit, considerable $\mathrm{U}$ mobilization in the UZ may seem to occur.

Dobson et al. (2008) made observations during 2005-06 at Nopal I on water transit times and found them to be highly heterogeneous with respect to time, location, and quantity. They noted that within the back adit area, a few zones where large volumes of water were collected have water transit times of $<24 \mathrm{hrs}$, presumably associated with focused flow through fractures. In most locations, however, there is a 1-6 month time lag between major precipitation events and seepage within the adit. To a first order approximation, the effective water-rock interaction times $\left(\tau_{w}\right)$ derived above from our model appear realistic.

\subsection{Variability of uranium systematics in unsaturated zone}

To further validate the model and to assess the variability of the UZ uranium isotopic systematics, we have made additional measurements of $U$ concentrations and ${ }^{234} U{ }^{238} U$ ratios in waters from the mine adit studied by Pickett and Murphy (1999). Previous mining activities resulted in the excavations of adits and shafts on a number of levels. A water-collection system was installed within a series of adits at the $+00 \mathrm{~m}$ level to allow for collection of rainfall seepage into the adit network. Refurbished in 2003 and 2005, two collection systems were available for our study: a drip collection system consisting of plastic sheeting and a series of Lexan trays designed to funnel water into plastic bottles (Dobson et al., 2008). Our measurements were done on seep waters collected at various times over a period from 2000 to 2006 . Water samples were filtered $(0.20 \mu \mathrm{m}$ or $0.45 \mu \mathrm{m}$ filters) and acidified to a $\mathrm{pH}$ of 1-2 with high purity nitric acid soon after collection. Uranium isotopes were measured at LANL using a GV Sector 54 mass spectrometer equipped with multiple Faraday cups and a Daly ion counting detector (Goldstein et al., 2006). The results are tabulated in

\section{Appendix 2.}

Goldstein et al. (2006) noted an increase of $U$ dissolution rates toward the front of adit, where the ore deposit is located (Fig. 4b). Rainfall in central Chihuahua is seasonal. The wet period of the year occurs in the summer and fall, with rainstorms mostly coming through the area in the months of July to October. See the historical precipitation data of CONAGUA (Comision Nacional del Agua Mexico's National Meteorological Service) for 1941-2005 (http://smn.cna.gob.mx/productos/maplluv/precipit.gif). Consistent with this historical data are also the rainfall record (1961-1972) of the Los Pozos weather station located about $5 \mathrm{~km}$ ESE of Nopal I, and the 2006 data collected by an 
automated weather station installed at the Nopal I site $\sim 65 \mathrm{~m}$ WSW of the adit. Based on these possible spatial and temporal influences, in plotting the Appendix 2 results as shown in Fig. 5, we group the data according to three locations: front, middle, and back of adit, and at each location we separately identify data for waters collected during two half-year periods: January-June and. JulyDecember. The group of samples collected during July-December can be considered to include waters of "wet season" (or of major flushing period), whereas the January-June group includes waters of "dry season" (or of minor-flushing period).

Figure 5 shows that $U$ concentrations in waters from the three locations clearly indicate a spatial trend of front $>$ middle $>$ back, with $U$ dissolution rates increasing toward the front of the adit where $\mathrm{U}$ mineralization resides (Fig. 4b; Goldstein et al., 2006). This trend is reversed for the ${ }^{234} \mathrm{U} /{ }^{238} \mathrm{U}$ signals owing to the dissolution of solids bringing in $U$ close to secular equilibrium. In the back-ofadit region, high ${ }^{234} \mathrm{U} /{ }^{238} \mathrm{U}$ activity ratios ranging from 2 to $>5$ are present.

Figure 5 further shows that at the middle and back of adit locations, the July-December data points as a group have higher ${ }^{234} \mathrm{U} /{ }^{238} \mathrm{U}$ ratios and lie above the January-June data array. Corresponding ${ }^{234} \mathrm{U}$ enrichment does not show up in two samples, SPC1040975 and SPC1041416, collected on 13 December 2006 from the front of the adit (cf. Appendix 2 and Fig. 5a; not shown in Fig. 5a is the SPC1040975 data point which falls outside the confines of the figure), however; their ${ }^{234} \mathrm{U} /{ }^{238} \mathrm{U}$ ratios could well be masked by the high $\mathrm{U}$ dissolution rate there.

Even though the samples were collected at different times over a 12-year period, the results that the ${ }^{234} \mathrm{U} /{ }^{238} \mathrm{U}$ ratios in samples collected during July to December are mostly higher than those from the January to June period may well link to the seasonal rainfall pattern of the area. This wet- vs. dryseason difference of ${ }^{234} \mathrm{U} /{ }^{238} \mathrm{U}$ ratios in vadose-zone waters is somewhat counter-intuitive in two respects, as one tends to associate wetter conditions with: (1) more intense dissolution of uranium, which would generally suppress the ${ }^{234} \mathrm{U} /{ }^{238} \mathrm{U}$ ratio, and (2) more frequent rainfall, which would have shorter non-flushing periods, hence less recoiled ${ }^{234} U$ to wash off the solid surfaces. To account for the observational patterns captured by the Fig. 5 plots, it appears that the July-December collections must contain uranium signals generated in the UZ by relatively prolonged non-flushing periods of the previous dry season. These wet season collections are amenable to picking up more recoil-produced ${ }^{234} \mathrm{U}$ as reflected by data from the middle and back of adit locations. Such ${ }^{234} \mathrm{U}$ pickup would be 
particularly evident in seepage water associated with earlier parts of the rainy season and representing the flushing of the system after the long dry season.

Three aspects should be involved in having waters with relatively elevated ${ }^{234} \mathrm{U} /{ }^{238} \mathrm{U}$ ratios following a dry season. They are: (1) the ${ }^{234} U$ build-up period that occurs mainly before the next wet season, (2) incomplete or inefficient flushing especially during the dry season, and (3) the time interval $\left(\tau_{w}\right)$ between the water entering and leaving the vadose zone. The latter two factors are influenced by rainfall intensity as well as the size and distribution of fractures. Therefore, the observed high ${ }^{234} \mathrm{U} /{ }^{238} \mathrm{U}$ may reflect a time lag for the recoil-produced ${ }^{234} \mathrm{U}$ to be flushed out of the system due to incomplete flushing of the UZ porous/fracture medium in the dry season (and some part of the wet season as well). Because of this time lag or incomplete flushing, one expects the effective non-flushing period to be greater for the wet season than the dry season. The large variability in flushing efficiency and water travel times, and its dependency on rainfall intensity render the precise assessment of the effective non-flushing period difficult in practice (i.e., an estimate based purely on seasonal rainfall information without considering the above factors can be misleading).

In addition to exhibiting the distinguished groupings noted above, the plots in Fig. 5 generally exhibit the linearity predicted by model Eq. (6). Some scatter of the data seen in the figure, in particular for the back of adit location, could reflect a number of factors. These include incomplete flushing owing to low rainfall or to ${ }^{234} \mathrm{U}$ having been recoil-driven into opposite surfaces of fine fractures, and variable uranium dissolution rate $\left(P_{d}\right)$ in rocks along different flow paths. The scatter may also result from the sampling artifacts of evaporative loss of water under low humidity conditions (particularly for the front of the adit), and from the fact that the actual sampling could have departed considerably from the ideal situation of retrieving waters representing only discrete major rain events. And finally, the assumption of a constant non-flushing time ( $\left.\tau_{o}\right)$ [cf. Eq. (6)] could be somewhat unrealistic. Despite the data scatter, two features stand out in the Fig. 5 plots: (1) Large variations in the ${ }^{238} \mathrm{U}$ concentration and ${ }^{234} \mathrm{U} / 238 \mathrm{U}$ ratio may occur in $\mathrm{UZ}$ waters. These variations can propagate as the water percolates downward to a saturated zone with limited groundwater flow and mixing, which appears to be the case for the Nopal I site (Goldstein et al., 2006). That is, the saturated system below the UZ may also see the variations in isotopic signals induced by the seasonal flow. (2) The linear trends and their relative positions defined by the data plots offer a ready means of testing the model's applicability to computing its parametric values. 
Table 1 summarizes values of $m$ and $b$ derived from fitting Eq. (6) to the Fig. 5 plots, along with model estimates of $P_{r}$ and $P_{d}$ and their spatial and temporal variations. To derive $P_{r}$ and $P_{d}$, we use $\tau_{o}$ values of $0.05 \mathrm{y}$ and $0.02 \mathrm{y}$, respectively, for water samples collected during the wet and dry seasons, taking into account the fact that compared to those collected during the dry season, waters collected during the wet season have experienced prolonged non-flushing periods of the previous dry season. The small scale of the setting allows us to assign a common $\tau_{o}$ for a given collection season. The summary presented in Table 1 serves to bring forward a certain feature of $U$ behavior in vadosezone waters as depicted by the modeling, in a setting with spatially varied $U$ distributions in the solid matrix. That is, moving away from the uranium ore body (cf. Fig. 4b), $P_{r}$ and $P_{d}$ both show gradational changes in the three adit areas.

\section{DISCUSSION}

\subsection{On the functionality of slope $(m)$ and $y$-intercept $(b)$}

Combining Eq. (4) with Eq. (5) may give rise to three different mathematical expressions for slope $(m)$ and $y$-intercept $(b)$ in a ${ }^{234} \mathrm{U} /{ }^{238} \mathrm{U}$ vs. $1 /{ }^{238} \mathrm{U}$ plot. They are given below. Among the three expressions, it can be argued that only the one we have chosen is viable.

(1) $m=\left(\tau_{w}+\tau_{o}\right) \lambda_{234 U} P_{r, 234 U}$ and $b=1$. That $b$ values are invariably fixed at unity is not supported by the observed data shown in Figs. 3 and 5, although the samples from the front and middle of the adit appear to have an intercept close to 1 considering the errors of the data. Besides, it requires the unrealistic assumption of keeping $\tau_{w}$, or the products of $\left(\tau_{w} \times P_{r, 234 U}\right)$ and $\left(\tau_{o} \times P_{r, 234 U}\right)$, as constant for all the samples.

(2) $m=\tau_{w} \lambda_{234 U} P_{r, 234 U}$ and $b=\left(\tau_{o} \lambda_{234 U} P_{r, 234 U}\right) /\left(\tau_{w} \lambda_{238 U} P_{d, 238 U}\right)+1$. Adopting this pair of expressions would require us to assume not only the product of $\left(\tau_{w} \times P_{r, 234 U}\right)$ but also the ratio of $\left(\tau_{o} \lambda_{234 U} P_{r, 234 U}\right) /\left(\tau_{w} \lambda_{238 U} P_{d, 238 U}\right)$ to be constant. It is difficult to imagine why the measured ${ }^{238} \mathrm{U}$ activities $\left(=\tau_{w} \lambda_{238 U} P_{d, 238 U}\right.$, see Eq. (4)) should remain constant. In other words, for Eq. (6) to be a linear equation, it would require us to assume constancy for $P_{r}$, $\tau_{w}$, and $\tau_{o} / P_{d}$. That $\tau_{o}$ and $P_{d}$ are required to maintain a constant ratio between them holds no physical basis. 
(3) $m=\lambda_{234 U} \tau_{o} P_{r, 234 U}$ and $b=\left(\lambda_{234 U} P_{r, 234 U} / \lambda_{238 U} P_{d, 238 U}\right)+1$. As pointed out earlier, of the four parameters $\left(P_{d}, P_{r}, \tau_{w}\right.$, and $\left.\tau_{o}\right)$ that define the linear array in a ${ }^{234} \mathrm{U} /{ }^{238} \mathrm{U}$ vs. $1{ }^{238} \mathrm{U}$ plot, only three may be taken a priori as "constants" in the linear fitting; the fourth one can be estimated from the measurements of ${ }^{234} \mathrm{U}$ and ${ }^{238} \mathrm{U}$ (e.g., via Eq. 4 or Eq. 5). Earlier in Section 3.1, we showed the use of Eq. (6) by assigning a representative value of $\tau_{o}$, which serves to fix $P_{r}$ (via the observed slope) and in turn, $P_{d}$ (via the observed $y$-intercept). The magnitude of $\tau_{w}$, which is allowed to vary in time and space to reflect the inhomogeneous nature of the fluid transport in UZ, is then estimated from Eq. (4) through the ${ }^{238} \mathrm{U}$ measurement.

Therefore, we interpret the slope and intercept of the linear relationship of Eq. (6) to reflect the length of the non-flushing period $\tau_{o}$ (i.e., the interval between major rainfall events during which no uptake of recoiled ${ }^{234} \mathrm{U}$ by percolating water occurs in the UZ), the $\alpha$-recoil rate of ${ }^{234} \mathrm{U}$, and the dissolution rate of uranium from the $\mathrm{UZ}$ solids. More specifically, the slope is a function of $\tau_{o}$ and $P_{r}$, and the $y$-intercept varies with the ratio $P_{r} / P_{d}$. Assuming $\alpha$-recoil to remain unchanged, the slope will increase as the non-flushing period lengthens, and a higher intercept will reflect a lower dissolution rate of $U$ in the $U Z$.

\subsection{Extending the model to Ra and Th isotopes}

Measurements of ${ }^{226 \mathrm{Ra} / 230} \mathrm{Th}$ in bulk ore and fracture-filling minerals at the Peña Blanca site indicated significant radioactive disequilibrium, suggesting mobility of Ra (Murrell et al., 1999; Leslie et al., 1999). They also point to the likelihood of disequilibria occurring in fluid and sorbed phases of the groundwater system for all four Ra isotopes: ${ }^{226} \mathrm{Ra}\left(t_{1 / 2}=1600 \mathrm{y}\right),{ }^{228} \mathrm{Ra}\left(t_{1 / 2}=5.75 \mathrm{y}\right)$, ${ }^{223} \mathrm{Ra}\left(t_{1 / 2}=11.4 \mathrm{~d}\right)$ and ${ }^{224} \mathrm{Ra}\left(t_{1 / 2}=3.66 \mathrm{~d}\right)$, with their respective thorium parents. At the Peña Blanca site, with a vadose-zone effective water transit time (for the $8 \mathrm{~m}$ distance between the ground surface and the top of the adit) of the order of $10^{-2}$ to $10^{-1} \mathrm{y}$ as shown earlier by the $\mathrm{U}$ isotope data and a retardation factor of radium, $R_{f, R a}^{*}$, of the order of $\sim 10^{4}$ in groundwater (Luo et al, 2000; $R_{f, R a}^{*}$ in the oxygenated vadose environments may be similar or even higher than this value), Eq. (3) can be simplified for ${ }^{223} \mathrm{Ra},{ }^{224} \mathrm{Ra}$ and ${ }^{228} \mathrm{Ra}$ as

$$
A^{*}=\frac{P}{R_{f, R a}^{*}}
$$


The dissolution input $\left(P_{d}\right)$ is usually negligible for these short-lived radionuclides. Thus the supply rates $(P)$ for ${ }^{224} \mathrm{Ra}$ and ${ }^{228} \mathrm{Ra}$ become (Luo et al., 2000)

$$
P_{224 R a}=P_{r, 224 R a}+R_{f, T h}^{*} A_{228 T h}^{*}=P_{r, 224 R a}+R_{f, R a}^{*} A_{228 R a}^{*}
$$

and

$$
P_{228 R a}=P_{r, 228 R a}+R_{f, T h}^{*} A_{232 T h}^{*}
$$

Substituting Eqs. (8a) and (8b) into Eq. (7) gives, respectively

$$
\frac{A_{224 R a}^{*}}{A_{228 R a}^{*}}=\frac{P_{r, 224 R a}}{R_{f, R a}^{*}} \frac{1}{A_{228 R a}^{*}}+1=\frac{m_{1}}{A_{228 R a}^{*}}+b_{1}
$$

and

$$
\frac{A_{228 R a}^{*}}{A_{232 T h}^{*}}=\frac{P_{r, 228 R a}}{R_{f, R a}^{*}} \frac{1}{A_{232 T h}^{*}}+\frac{R_{f, R a}^{*}}{R_{f, T h}^{*}}=\frac{m_{2}}{A_{232 T h}^{*}}+b_{2}
$$

These two equations are linear in character in the $y-x$ plots of $A_{224 R a}^{*} / A_{228 R a}^{*}$ vs. $1 / A_{228 R a}^{*}$ and $A_{228 R a}^{*} / A_{232 T h}^{*}$ vs. $1 / A_{232 T h}^{*}$. The slopes are $m_{1}=P_{r, 224 \mathrm{Ra}} / R_{f, R a}^{*}$ and $m_{2}=P_{r, 228 \mathrm{Ra}} / R_{f, R a}^{*}$. The $y$-intercepts are $b_{1}=1$ and $b_{2}=R_{f, R a}^{*} / R_{f, T h}^{*}$.

For long-lived ${ }^{226} \mathrm{Ra}, \lambda R_{f}^{*} \tau_{w}<<1$ and the Eq. (3) relationship takes the form

$$
A_{226 R a}^{*}=\lambda_{226 R a} \tau_{w}\left(P_{d, 226 R a}+P_{r, 226 R a}+R_{f, T h}^{*} A_{230 T h}^{*}\right)
$$

This relationship is valid only when there is fluid transport (i.e., $\tau_{w} \neq 0$ ). As no fluid transport and ${ }^{226} \mathrm{Ra}$ dissolution take place during the non-flushing period $\tau_{o}$ in the vadose zone, Eq. (10a) should be rewritten as

$$
A_{226 R a}^{*}=\lambda_{226 R a} \tau_{o}\left(P_{r, 226 R a}+R_{f, T h}^{*} A_{230 T h}^{*}\right)+\lambda_{226 R a} \tau_{w}\left(P_{d, 226 R a}+P_{r, 226 R a}+R_{f, T h}^{*} A_{230 T h}^{*}\right)
$$


Following the uranium modeling, given $\tau_{\mathrm{o}}$, values of $P_{r}, P_{d}$, and $\tau_{\mathrm{w}}$ can be constrained. Besides, one can estimate the in-situ retardation factor of $\mathrm{Ra}\left(R_{f, R a}^{*}\right)$ from the slope $\left(m_{1}\right)$ of Eq. $(9 \mathrm{a})$ or from the slope $\left(m_{2}\right)$ of Eq. $(9 \mathrm{~b})$. The retardation factor of Th $\left(R_{f, T h}^{*}\right)$ can also be estimated from the $y$-intercept $\left(b_{2}\right)$ of Eq. (9b). With these parameters known, the dissolution rate of ${ }^{226} \operatorname{Ra}\left(P_{d, 226 R a}\right)$ can also be estimated from Eq. (10b). Furthermore, plots of Eqs. (9a) and (9b) are expected to yield slope values with a similar ratio of $\left(P_{r} / R_{f}^{*}\right)$, and a plot of Eq. (9a) for measured ${ }^{224} \mathrm{Ra}$ and ${ }^{228} \mathrm{Ra}$ activities is expected to yield $y$-intercept values close to unity. The multiple estimates constrained by the radium isotopes may serve to internally test and validate the model. As mass-spectrometric analyses of ${ }^{226} \mathrm{Ra}$ and ${ }^{228} \mathrm{Ra}$ (Volpe et al., 1991, Foster et al., 2004) and delay-coincidence counting of ${ }^{224} \mathrm{Ra}$ and ${ }^{223} \mathrm{Ra}$ (e.g., Moore and Arnold, 1996) in small-volume fluid samples continue to advance, such tests are feasible.

\section{CONCLUSION}

We have made an initial attempt to model the non-steady state fluid phase distribution of naturally occurring $\mathrm{U}$ - and Th-series isotopes in unsaturated water-rock systems. This attempt is complementary to previous efforts in assessing the transport behavior of $\mathrm{U}$-series radionuclides in soils on drainage-basin scales (Porcelli, 2008). Based on mass-balance considerations, our model quantitatively describes the preferential fluid and nuclide transport with particular relevance to the vadose zone. The model allows assessment of in-situ radioisotope migration in dissolved and colloidal phases in terms of effective retardation factor and rock-water interaction (or water transit) time. For uranium, water passing through the unsaturated zone has its $U$ concentration and ${ }^{234} U /{ }^{238} U$ ratio modified by $U$ dissolution from rocks and $\alpha$-recoil input of ${ }^{234} U$ from rock/fracture surfaces. The extent of the modification gives rise to waters showing a linear relationship between reciprocal $U$ concentration and ${ }^{234} \mathrm{U} /{ }^{238} \mathrm{U}$ ratio. The slope and intercept of the linearity reflect water-rock interaction and intermittent flushing times, as well as $U$ dissolution and $\alpha$-recoil rates. Despite the fact that at this stage of development the model may border on being simplistic in certain aspects (e.g., no attempt to parameterize any fracture/preferential flow in the UZ solid matrix), its concept appears to have been essentially borne out by the observed variations of uranium isotopes in vadose-zone water collected during 1995-2006 from a site in the Peña Blanca mining district, Mexico, where the Nopal I uranium deposit is located. Further proof-of-concept validations can in principle be made with radium, the multiple isotopes of which allow checks for internal consistency of data as constrained by 
the modeling. One interesting feature captured by the non-steady state model is that prolonged nonflushing time may give rise to higher ${ }^{234} \mathrm{U} /{ }^{238} \mathrm{U}$ ratios in vadose-zone waters. It may bear implications on the use of the temporal changes of ${ }^{234} \mathrm{U} /{ }^{238} \mathrm{U}$ observed in cave calcites to deduce past changes in regional hydrology and/or climate.

\section{Acknowledgments}

We thank Schon Levy, Ardith Simmons, and Ron Oliver of LANL for valuable assistance, discussions, and comments at various stages of the work. We also thank Paul Cook of LBNL and our Universidad Autónoma de Chihuahua colleagues for their assistance in sample collection. This research was supported (DE-AC02-05CH11231) by the US Department of Energy's Office of Civilian Radioactive Waste Management (OCRWM). The views expressed in this paper do not necessarily reflect those of OCRWM. Comments made by Ian Bourg, William M. Murphy and an anonymous reviewer on an early version substantially helped improve our presentation. This work is dedicated to the late Dr. Miro Ivanovich who had contributed so much to the field. 


\section{APPENDIX 1}

We consider the gain or loss $\left(\Delta C^{*}\right)$ of a property $C^{*}$ (e.g., dissolved plus colloidal concentrations of a radioisotope) in a small parcel $(\Delta x \times \Delta y \times \Delta z)$ of water moving with velocity $\mathbf{u}$ :

$$
\begin{array}{cc}
\Delta C^{*}(x, y, z, t) & =\frac{\partial C^{*}}{\partial t} \Delta t+\frac{\partial C^{*}}{\partial x} \Delta x+\frac{\partial C^{*}}{\partial y} \Delta y+\frac{\partial C^{*}}{\partial z} \Delta z \\
\text { or its rate of change: } \quad & \frac{d C^{*}}{d t}=\frac{\partial C^{*}}{\partial t}+u_{x} \frac{\partial C^{*}}{\partial x}+u_{y} \frac{\partial C^{*}}{\partial y}+u_{z} \frac{\partial C^{*}}{\partial z}
\end{array}
$$

Equation (A2) can be viewed as the continuity (mass conservation) equation of property $C^{*}$ at $(x, y, z, t)$. Taking $d / d t$ in the equation as the Lagrangian derivative operator (conventionally written as $\mathrm{D} / \mathrm{D} t$; e.g., Tritton, 1988) to denote the rate of change following the small water parcel, we see that the time rate of change of $C^{*}$ in a given water parcel due to gain or loss through non-conservative (i.e., chemical and radiochemical) processes is balanced by the terms on the right-hand side of the equation. For a one-dimensional case at stationary state (i.e., $\partial C^{*} / \partial t=0$ ), Eq.(A2) resembles the mass balance model equation of $\mathrm{Ku}$ et al. (1992) describing the spatial distribution of a radionuclide. [Note that the $d\left(C+C_{a}\right) / d t$ term in Ku et al. (1992)'s Eq. (18.1) should be considered as $\partial\left(C+C_{a}\right) / \partial t$.] By focusing on the concentration variation of a radionuclide within the water parcel rather than tracing the variation spatially along a given dimension or transport path (as in $\mathrm{Ku}$ et al., 1992), the present model provides constraints on the time rate of change of radionuclide concentration in a given water parcel in the context of water-rock interaction.

We make two assumptions: (1) exchanges between the dissolved, sorbed, and colloidal pools are rapid such that the ratio $C_{a} / C^{*}$ remains constant, $C_{a}$ being the concentration in the sorbed pool; and (2) precipitation rate is first order with respect to $C^{*}\left(=-k_{p} C^{*}\right.$; cf. Ku et al. 1992, 1998). Since $C^{*}=C+$ $C_{\mathrm{c}}$, where $C^{*}, C$ and $C_{\mathrm{c}}$ are, respectively, the measured, dissolved, and colloidal concentrations of a radioisotope with decay constant $\lambda$, Eq. (A2) can be rewritten as

$$
\frac{d C^{*}}{d t}=P-k_{1} C+k_{2} C_{a}-\beta_{1} C_{c}+\beta_{2} C_{a}-k_{p} C^{*}-\lambda C^{*}
$$


where $k_{1}$ and $k_{2}$ are, respectively, the first-order sorption and desorption rate constants, and $\beta_{1}$ and $\beta_{2}$ refer to the corresponding constants for colloids in the solution. For the immobile sorbed pool, the rates of spatial and temporal changes in isotope concentrations under non-steady state are difficult to predict as the chemical and isotopic exchanges between the mobile (dissolved and colloidal) and immobile pools involve kinetics that are not well understood. As a first-order approximation, we assume that the exchanges between the mobile and immobile pools are rapid enough (compared to the radioactive decay rate) are such that for a given isotope, its rate of radioactive decay in the immobile pool is nearly maintained by its sorption rate through exchanges with the dissolved and/or colloidal pools. This assumption implies that $\partial C_{\mathrm{a}} / \partial t=$ constant $\times \partial C^{*} / \partial t$ while $d C_{\mathrm{a}} / d t \neq 0$, and that $\partial C_{\mathrm{a}} / \partial t$ is small relative to the rate of exchange between the mobile and immobile pools. Under this assumption, we have $C_{\mathrm{a}} / C=k_{1} / k_{2}$ and $C_{\mathrm{a}} / C_{\mathrm{c}}=\beta_{1} / \beta_{2}$ for stable isotopes and the following equation for radioisotopes:

$$
k_{1} C-k_{2} C_{a}+\beta_{1} C_{c}-\beta_{2} C_{a}=\lambda C_{a}
$$

This equation depicts a quasi-equilibrium state of a radioisotope between the mobile (dissolved and colloidal) and immobile (sorbed) pools; it is not a mass-balance equation for the radioisotope in the sorbed pool sensu stricto. Combining Eqs. (A3) with (A4) and writing in terms of the effective retardation factor $R_{f}^{*}\left(=1+C_{a} / C^{*}+k_{p} / \lambda\right.$; cf. Ku et al. 1992, 1998), we arrive at Eq. (1) of the main text. 
APPENDIX 2

Uranium concentrations and ${ }^{234} \mathrm{U} /{ }^{238} \mathrm{U}$ activity ratios in $\mathrm{UZ}$ waters at the Nopal I $\mathrm{U}$ deposit, collected from the mine adit at +00 level near well PB1 during 2000-2006, including two samples collected in Sept. 1995 by Pickett and Murphy (1999).

\begin{tabular}{|c|c|c|c|c|}
\hline Location* & Sample ID & $\begin{array}{c}\text { Date } \\
\text { Collected }\end{array}$ & $\begin{array}{c}{[\mathrm{U}]^{\#}} \\
\mathrm{dpm} / \mathrm{L}\end{array}$ & $\begin{array}{l}{ }^{234} \mathrm{U} /{ }^{238} \mathrm{U}^{\#} \\
\text { activity ratio }\end{array}$ \\
\hline Front of Adit near UC 1a & $030710-05$ & 7-Mar-01 & 9.710 & 1.023 \\
\hline Front of Adit near UC 3 & AS-1 & $25-F e b-00$ & 51.10 & 1.060 \\
\hline Front of Adit UC 4 & SPC1025062 & 11-Apr-05 & 4.506 & 0.999 \\
\hline Front of Adit near UC 5 & AS-2 & $25-F e b-00$ & 27.54 & 0.939 \\
\hline Front of Adit near UC 5 & 030701-04 & 7-Mar-01 & 12.31 & 0.920 \\
\hline Front of Adit UC 5 & SPC1025063 & 11-Apr-05 & 2.502 & 1.326 \\
\hline Front of Adit LBL 39B & SPC1038735 & 11-Jan-06 & 67.78 & 1.186 \\
\hline Front of Adit LBL 39B & SPC1040975 & 13-Dec-06 & 0.521 & 1.465 \\
\hline Front of Adit LBL 47E & SPC1038778 & 11-Jan-06 & 315.5 & 0.817 \\
\hline Front of Adit LBL 47E & SPC1041416 & 13-Dec-06 & 6.582 & 0.854 \\
\hline Middle of Adit UC 6 & SPC1025066 & 11-Apr-05 & 0.317 & 1.278 \\
\hline Middle of Adit UC 6 & SPC1038243 & $10-N o v-05$ & 0.032 & 1.207 \\
\hline Middle of Adit UC 7 & AS-3 & $25-F e b-00$ & 3.011 & 1.177 \\
\hline Middle of Adit UC 7 & 030701-3 & 7-Mar-01 & 20.12 & 1.173 \\
\hline $23 \mathrm{~m}$ from adit entrance & ADIT95-9 & Sep-95* & 0.661 & 2.845 \\
\hline Middle of Adit UC 7/7a & SPC1025056 & 29-Jan-04 & 13.42 & 1.313 \\
\hline Middle of Adit UC 7/7a & SPC1025057 & 29-Jan-04 & 63.59 & 0.999 \\
\hline Middle of Adit UC 8 & SPC1025034 & 1-Jul-03 & 0.186 & 4.879 \\
\hline Middle of Adit UC 8 & SPC1025035 & 26-Sep-03 & 3.357 & 1.504 \\
\hline Middle of Adit UC 8 & SPC1025042 & 15-Oct-03 & 21.96 & 2.291 \\
\hline Middle of Adit UC 8 & SPC1025055 & 29-Jan-04 & 1.531 & 1.804 \\
\hline Middle of Adit UC 8 & SPC1025064 & 11-Apr-05 & 1.232 & 1.581 \\
\hline Middle of Adit LBL 23B & SPC1038263 & 10-Jan-06 & 16.74 & 1.242 \\
\hline Middle of Adit LBL 27C & SPC1038227 & 9-Nov-05 & 4.671 & 1.237 \\
\hline Middle of Adit LBL 27C & SPC1040246 & 22-Mar-06 & 0.515 & 1.340 \\
\hline Middle of Adit LBL 32A & SPC1040259 & 22-Mar-06 & 0.322 & 1.730 \\
\hline Middle of Adit LBL 34E & SPC1040953 & 12-Dec-06 & 0.746 & 2.731 \\
\hline Back of Adit near UC 9 & 030701-02 & 7-Mar-01 & 0.896 & 2.588 \\
\hline Back of Adit UC 9 & SPC1025033 & 1-Jul-03 & 0.266 & 2.570 \\
\hline Back of Adit UC 9 & SPC1025036 & 26-Sep-03 & 2.104 & 4.197 \\
\hline Back of Adit UC 9 & SPC1025041 & 15 -Oct-03 & 0.331 & 5.181 \\
\hline Back of Adit UC 9 & SPC1025054 & 29-Jan-04 & 0.426 & 4.399 \\
\hline Back of Adit UC 10 & SPC1025032 & 1-Jul-03 & 2.120 & 3.625 \\
\hline Back of Adit UC 10 & SPC1025040 & $15-O c t-03$ & 3.373 & 4.431 \\
\hline Back of Adit UC 10 & SPC1025053 & 29-Jan-04 & 2.501 & 2.573 \\
\hline Back of Adit UC 10 & SPC1025065 & 11-Apr-05 & 11.15 & 4.315 \\
\hline Back of Adit LBL 4D & SPC1038005 & 8-Nov-05 & 8.984 & 4.875 \\
\hline Back of Adit LBL 8B & SPC1037917 & 8-Nov-05 & 9.380 & 4.392 \\
\hline Back of Adit LBL 11A & SPC1037936 & 8-Nov-05 & 1.075 & 5.526 \\
\hline Back of Adit LBL 18A & SPC1037978 & 10-Nov-05 & 0.174 & 4.489 \\
\hline Back of Adit LBL 18A & SPC1038255 & 10-Jan-06 & 0.066 & 2.966 \\
\hline Back of Adit LBL 18A & SPC1040296 & 23-Mar-06 & 1.034 & 2.528 \\
\hline Back of Adit LBL 18A & SPC2041957 & 26-Aug-06 & 0.386 & 3.697 \\
\hline $8.5 \mathrm{~m}$ into N. part of adit & ADIT95-6 & Sep-95* & 0.14 & 5.072 \\
\hline
\end{tabular}

* Samples with the LBL notation were collected with the fine grid collection system; other samples were collected with the plastic sheeting. See Fig. 4 for locations of samples with LBL and UC notations.

${ }^{\#}{ }^{238} \mathrm{U}$ and ${ }^{234} \mathrm{U}$ activities were computed from the measured mass units using $\lambda_{238}=1.551 \times 10^{-10} \mathrm{y}^{-1}$ and $\lambda_{234}=$ $2.826 \times 10^{-6} \mathrm{y}^{-1}$. Typical uncertainties $(2 \sigma)$ are $<0.5 \%$ for $[\mathrm{U}]$ and $<0.2 \%$ for ${ }^{234} \mathrm{U} /{ }^{238} \mathrm{U}$. 
Table 1. Summary of model parameters $m, b, P_{r}$ and $P_{d}$ derived from fitting Eq. (6) to the Fig. 5 plots for UZ waters collected from the adit system at the Nopal I U deposit near well PB1. Seasonal changes of the UZ non-flushing times ( $0.05 \mathrm{y}$ vs. $0.02 \mathrm{y})$ are used in the derivation.

\begin{tabular}{cccccc}
\hline $\begin{array}{c}\text { Sampling } \\
\text { Location }\end{array}$ & $\begin{array}{c}\text { Collection } \\
\text { Period }\end{array}$ & $\left.\begin{array}{c}\text { Slope } \\
(m, \mathrm{dpm} \mathrm{L}\end{array}\right)$ & $\begin{array}{c}y \text {-intercept } \\
(b)\end{array}$ & $\begin{array}{c}P_{r} \\
\left(\mathrm{dpm} \mathrm{L}^{-1} \mathrm{y}^{-1}\right)\end{array}$ & $\begin{array}{c}P_{d} \\
\left(\mathrm{dpm} \mathrm{L}^{-1} \mathrm{y}^{-1}\right)\end{array}$ \\
\hline Front of adit* & Dry season & 0.941 & 0.90 & 47 & $>47 * *$ \\
\hline Middle of adit & Wet season & 0.610 & 1.64 & 12 & 19 \\
Middle of adit & Dry season & 0.084 & 1.28 & 4.2 & 15 \\
\hline Back of adit & Wet season & 0.059 & 4.42 & 1.2 & 0.35 \\
Back of adit & Dry season & 0.035 & 2.45 & 1.8 & 1.21 \\
\hline
\end{tabular}

* Samples from this area were collected less frequently due to the reduced seepage rates, which may result from increased evaporation as the area is close to the adit entrance.

** Only a minimal value can be determined by the model. That ${ }^{234} \mathrm{U} /{ }^{238} \mathrm{U}$ activity ratios are lower than the secular equilibrium value of unity suggests dissolution of material that has been previously subjected to preferential removal of ${ }^{234} \mathrm{U}$ by the recoil effect - an aspect not covered in our model formulation. The nominal value given is for $y$-intercept $b \approx 1$. 


\section{Figure Captions}

Fig. 1. Map (shown with UTM coordinates) of the Nopal I uranium deposit in the Peña Blanca mining district, showing older wells (Peña Blanca, PB4 and Pozos) and boreholes drilled in 2003 (PB1, PB2 and PB3). The unsaturated zone water samples were collected from an abandoned mine adit located at the +00 level ( $(8 \mathrm{~m}$ below the exposed level surface and $\sim 210 \mathrm{~m}$ above the water table) near PB1. Base map taken from Instituto de Estadística, Geografía e Informática 1:50,000 El Sauz topographic map (H13C46).

Fig. 2. Schematic representation of the rock-water interaction model of Ku et al. (1992), showing radionuclides to reside in three pools: dissolved, sorbed on solid surface, and solid. The dissolved pool includes colloids as a mobile particle pool, but this is only to a first-order approximation (see Porcelli and Swarzenski, 2003). Arrows with solid and dashed lines represent reversible and irreversible processes, respectively. Dissolution and precipitation are considered as irreversible processes because the precipitated minerals are not necessarily the same as those that are dissolved, and because these processes are not rapid enough to maintain local equilibrium between the dissolved and solid pools. Modified from Fig. 1 of Ku et al. (1998).

Fig. 3. (a) Plot of measured ${ }^{234} U /{ }^{238} U$ activity ratio vs. reciprocal ${ }^{238} U$ activity in Nopal I waters as reported by Pickett and Murphy (1999). The dashed line delineates the positive linear correlation for the four waters from the UZ. Its slope and intercept, according to our model, contain information on $P_{r}$ and $P_{d}$. (b) ${ }^{234} \mathrm{U} /{ }^{238} \mathrm{U}$ activity ratio (solid lines) and ${ }^{238} \mathrm{U}$ concentration (dashed line) as a function of water transit time $\left(\tau_{w}\right)$, showing a rapid decrease of ${ }^{234} \mathrm{U} /{ }^{238} \mathrm{U}$ to a relatively constant level within a couple of weeks after the water comes in contact with rocks. The level-off ${ }^{234} \mathrm{U} /{ }^{238} \mathrm{U}$ value is dictated by the $P_{r} / P_{d}$ ratio during water-rock interaction. The two solid curves drawn show that the low ${ }^{234} \mathrm{U} /{ }^{238} \mathrm{U}$ activity ratio of 1.39 of the carbonate aquifer sample (see (a)) requires a $P_{r} / P_{d}$ activity ratio of about 0.4 in the SZ, which is about three times smaller than that of $1.1\left(=9 \mathrm{dpm} \mathrm{L}{ }^{-1} \mathrm{y}^{-1} / 8.3 \mathrm{dpm} \mathrm{L}-\right.$ $\left.{ }^{1} \mathrm{y}^{-1}\right)$ in the UZ.

Fig. 4. (a) Schematic map of the UC (Universidad Autónoma de Chihuahua) unsaturated zone sample collection sites (labeled 1 through 10) from the mine adit located on the +00 level. Red sites represent front adit locations, yellow sites represent middle adit locations, and green sites represent back adit locations. (b) Plan view map of the Nopal I uranium deposit, indicating the location of the +00 adit, 
the seepage collector arrays (with a depiction of the array numbering system), and the PB-1 well. The locations of $U$ ore body are from Pearcy et al. (1995). Grid divisions are in meters. Adit locations depicted using same color coding as in (a).

Fig. 5. Plot of ${ }^{234} U{ }^{238} U$ activity ratio vs. reciprocal ${ }^{238} U$ activity measured in seepage waters collected at various times over the period 1995-2006, from three general locations of the mine adit shown in Fig. 4, using data listed in Appendix 2. (a) Front of Adit, (b) Middle of Adit, and (c) Back of Adit. The data point for the Front of Adit sample LBL 39B is not shown in (a) as it is located outside the plot. 


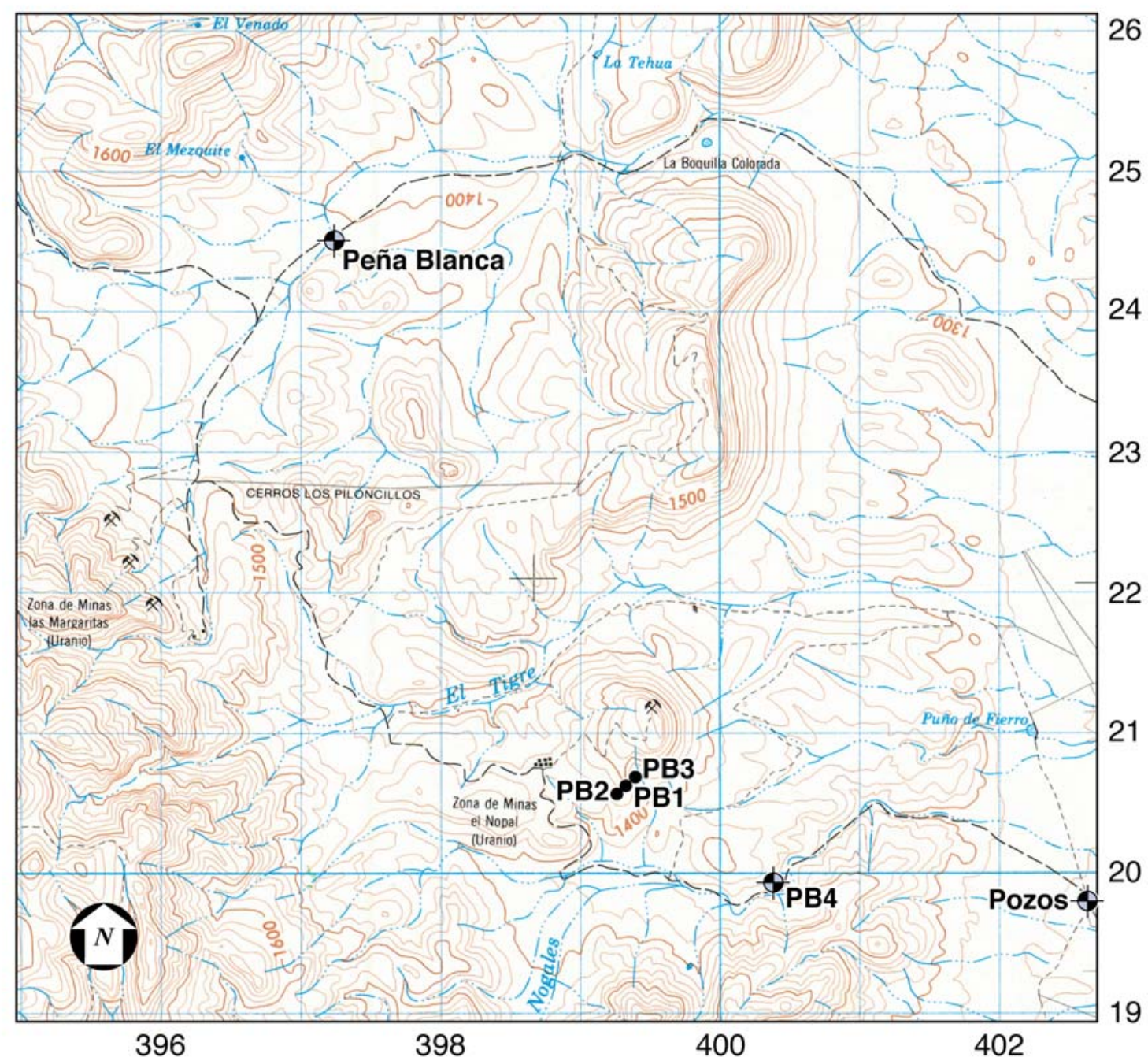

\section{Legend}

Existing Wells

- New Peña Blanca Boreholes

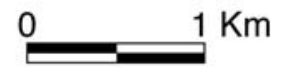

Contour Interval $=20$ Meters 


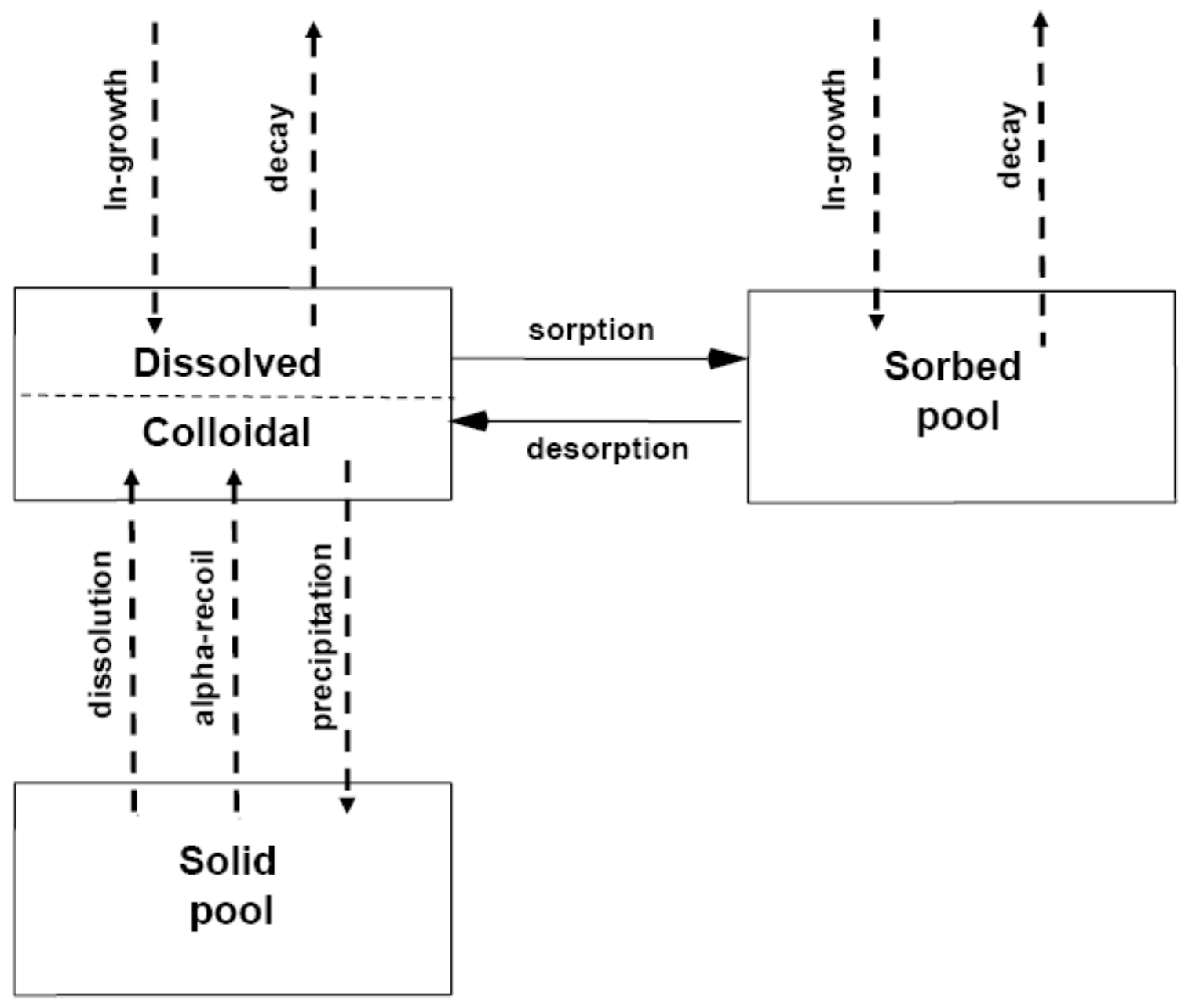



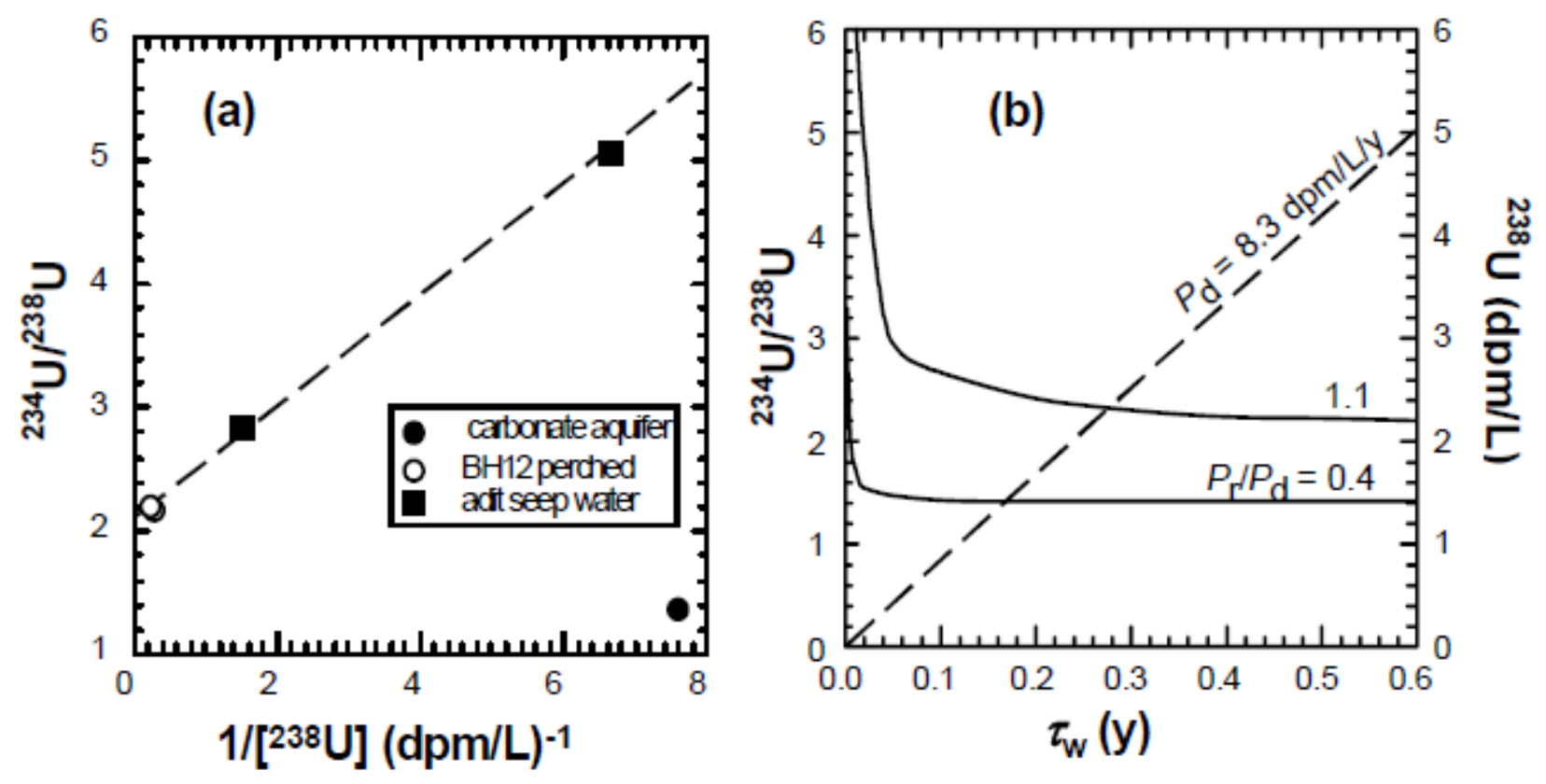


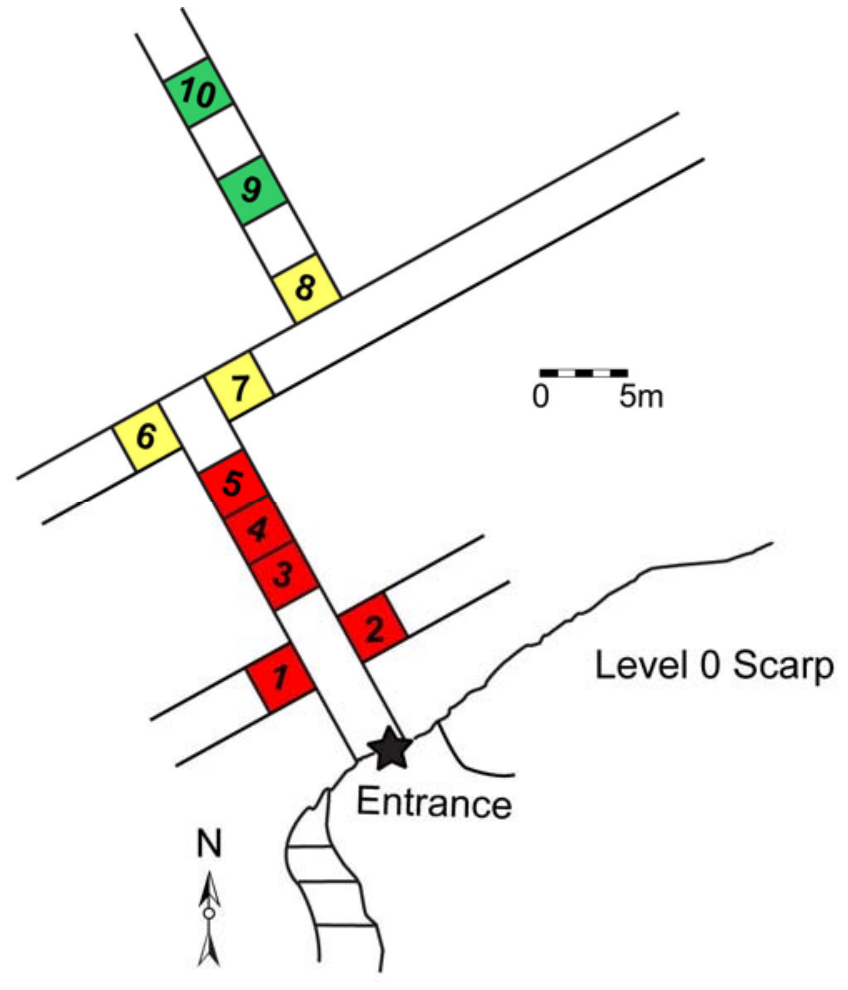

(a)

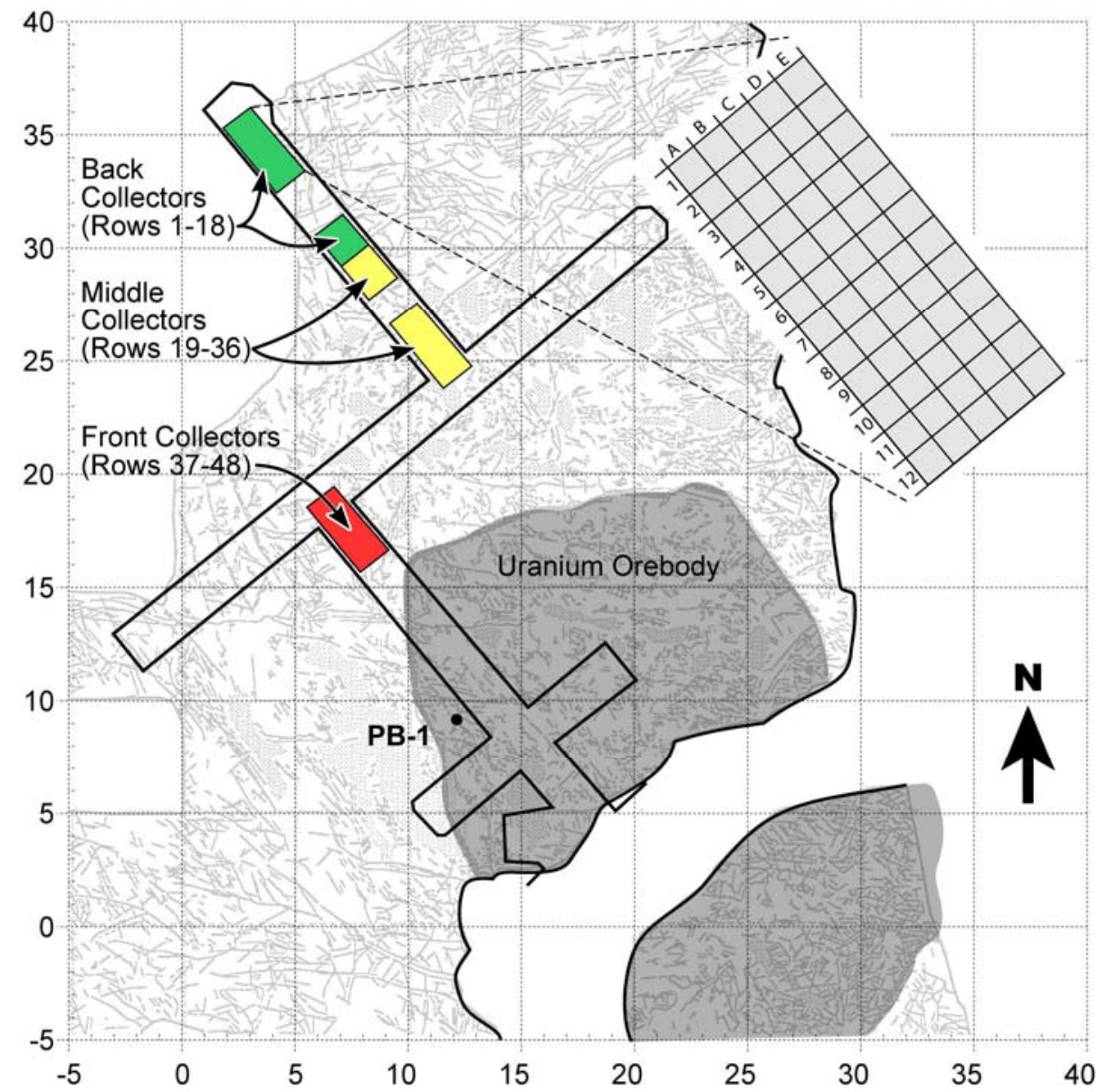

(b) 
(a)

\section{Front of Adit}

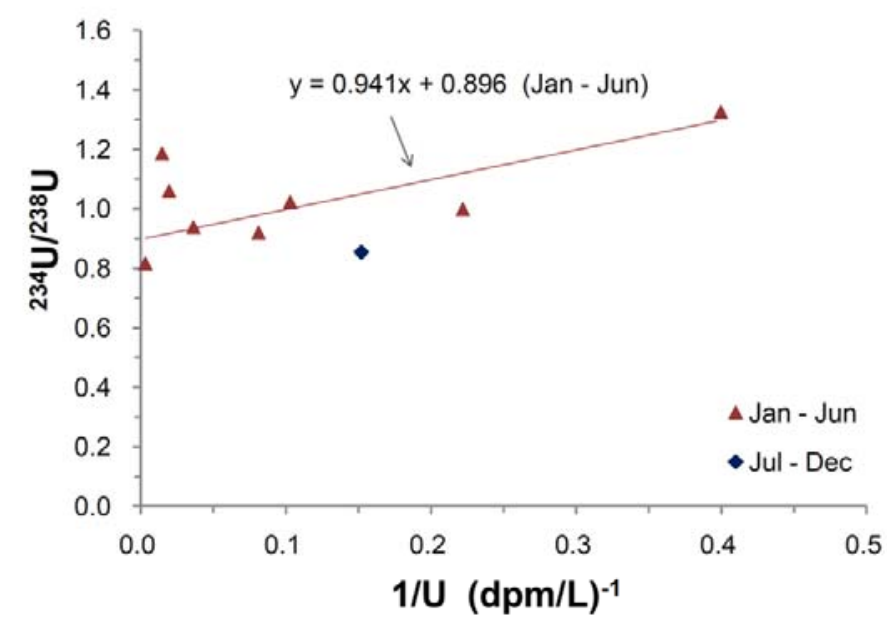

(b) Middle of Adit

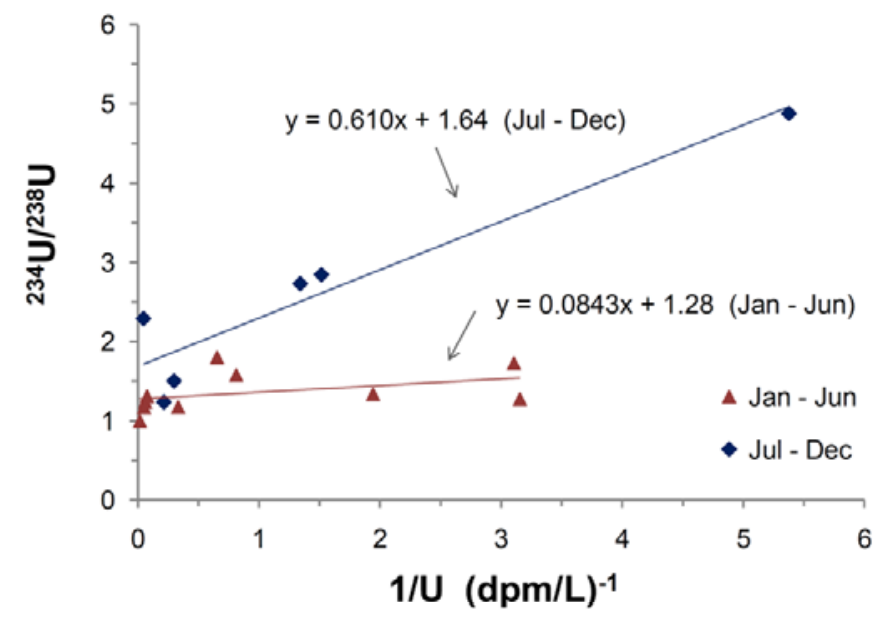

(c)

Back of Adit

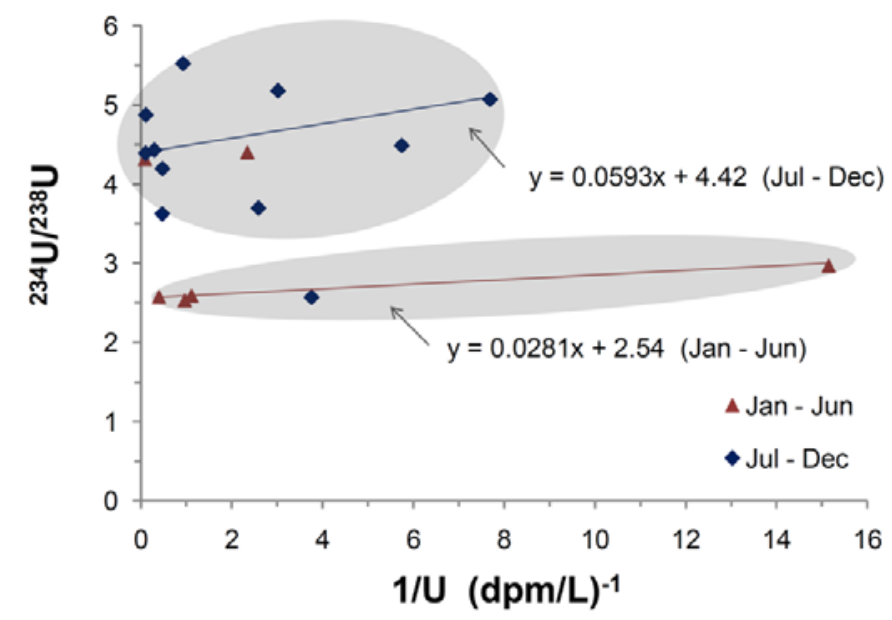




\section{References}

Contardi J.S., Turner D.R. and Ahn T.M, (2001) Modeling Colloid Transport for Performance Assessment. J. Contam. Hydro. 47, 323-333.

Dobson, P.F., Cook, P.J., Ghezzehei, T., Rodriguez, J.A., and de la Garza, R. (2008) Heterogeneous seepage at the Nopal I Uranium mine, Chihuahua, Mexico. In: Earth Sciences Division Research Summaries 2006-2007, Lawrence Berkeley National Laboratory Report 771E, p. 129, http://wwwesd.lbl.gov/PUBLICATIONS/RESEARCHSUMMARIES/2006-2007/pdf/lbnl-771E.pdf.

Foster D.A., Staubwasser M. and Henderson G.M. (2004) ${ }^{226}$ Ra and Ba concentrations in the Ross Sea measured with multicollector ICP mass spectrometry. Mar. Chem. 87, 59-71.

Gascoyne M. (1982) Geochemistry of the actinides and their daughters. In: Uranium Series Disequilibrium: applications to Environmental Problems (eds. M. Ivanovich and R.S. Harmon), pp. 33-55, Clarendon Press, Oxford.

Goldstein S.J., Luo S., Ku T.L. and Murrell M.T. (2006) Uranium-series constraints on radionuclide transport and groundwater flow at the Nopal I uranium deposit, Sierra Peña Blanca, Mexico. Proc. Intern. High Level Radioactive Waste Management Conf. (IHLRWM, American Nuclear Society) Las Vegas, NV, pp 215-222.

Goodell P.C. (1985) Chihuahua City uranium province, Chihuahua, Mexico. In: Uranium Deposits in Volcanic Rocks, Proc. series, IAEA TC-4907 19, International Atomic Energy Agency, Vienna, Austria, p. 97-124.

Hellstrom J.C. and McCulloch M.T. (2000) Multi-proxy constraints on the climatic significance of trace element records from a New Zealand speleothem. Earth Planet. Sci. Lett. 179, 287-297.

Kaufman A., Wasserburg G.J., Porcelli D., Bar-Mathews M., Ayalon A. and Halicz L. (1998) U-Th isotope systematics and $\mathrm{U}$-series ages of speleothems from Soreq Cave, Israel and climatic correlations. Earth Planet. Sci. Lett. 156, 141-155.

Krishnaswami S., Graustein W. C., Turekian K. K. and Dowd J. F. (1982) Radium, thorium and radioactive lead isotopes in groundwaters: Application to the in situ determination of adsorptiondesorption rate constants and retardation factors. Water Resources Res. 18, 1633-1675. 
Ku T. L., Luo S., Leslie B.W. and Hammond D.E. (1992) Decay series disequilibria applied to the study of rock-water interaction and geothermal systems. In: Uranium Series Disequilibrium: Applications to Earth, Marine and Environmental Sciences (eds. M. Ivanovich and R.S. Harmon), pp. 631-668, Clarendon Press, Oxford.

Ku T.L., Luo S., Leslie B.W. and Hammond D.E. (1998) Assessing in-situ radionuclide migration from natural analog studies: response to McKinley and Alexander (1996). Radiochim. Acta 80, 219-223.

Leslie, B.W., Pearcy, E.C., and Prikryl, J.D. (1993) Oxidative alteration of uraninite at the Nopal I deposit, Mexico: Possible contaminant transport and source term constraints for the proposed repository at Yucca Mountain. In: Scientific Basis for Nuclear Waste Management XVI (eds. C.G. Interrante and R.T. Pabalan) Materials Research Society Proc. 294, pp. 505-512.

Leslie B.W., Pickett D.A. and Pearcy E.C. (1999) Vegetation-derived constrants on he mobilization and potential transport of radionuclides from the Noal natural analog site, Mexico. In: Scientific Basis for Nuclear Waste Management XXII (eds. D.J. Wronkiewicz and J.H. Lee) Material Research Society Proc. 556, pp. 833-842.

Luo S., Ku T.L, Roback R., Murrell M. and McLing T.L. (2000) In-situ radionuclide transport and preferential groundwater flows at INEEL (Idaho): Decay-series disequilibrium studies. Geochim. Cosmochim. Acta 64, 867-881.

Moore W.S. and Arnold R. (1996) Measurement of ${ }^{223} \mathrm{Ra}$ and ${ }^{224} \mathrm{Ra}$ in coastal waters using a delayed coincidence counter. J. Geophys. Res. 101, 1321-1329.

Murphy W.M. (1995) Natural analogs for Yucca Mountain. Radwaste Mag. 2, 44-50.

Murphy, W.M. (2000) Natural analogs and performance assessment for geologic disposal of nuclear waste. In: Scientific Basis for Nuclear Waste Management XXIII (eds. R.W. Smith and D.W. Shoesmith), Materials Research Society Proc. 608, pp. 533-544.

Murphy W.M. and Pearcy E.C. (1993) Performance assessment significance of natural analog studies at Peña Blanca, Mexico, and at Santorini, Greece. In: Fifth EC Natural Analogue Working Group Meeting and Alligator River Analogue (ARAP) Final Workshop (eds. H.von Maravic and J. Smellie), EUR 15176 EN, European Comm., Luxembourg, pp. 219-224. 
Murrell M.T., Goldstein S.J.and Dixon P.R. (1999) Uranium decay series mobility at Peña Blanca, Mexico, Implications for nuclear repository stability. Proc. 8th EC Natural Analogue Working Group Meeting, Strasbourg, France, 1999, p. 1-4.

Pearcy, E.C., Prikryl J.D., and Leslie B.W. (1995) Uranium transport through fractured silicic tuff and relative retention in areas with distinct fracture characteristics. Appl. Geochem. 9, 685-704.

Pearcy E.C., Prikryl J.D., Murphy W.M. and Leslie B.W. (1994) Alteration of uraninite from the Nopal I deposit, Peña Blanca District, Chihuahua, Mexico, compared to degradation of spent nuclear fuel in the proposed U.S. high-level nuclear waste repository at Yucca Mountain, Nevada. Appl. Geochem. 9, 713-732.

Pickett D.A. and Murphy W.M. (1999) Unsaturated zone waters from the Nopal I natural analog, Chihuahua, Mexico - Implications for radionuclide mobility at Yucca Mountain. In: Scientific Basis for Nuclear Waste Management XXII, Materials Research Society Proc. 556, 809-816.

Porcelli D. (2008) Investigating groundwater processes using U- and Th-series nuclides. In: U/Th Radionuclides in Aquatic Systems (eds. S. Krishnaswami and J.K. Cochran), Elsevier, pp. 105153.

Porcelli D. and Swarzenski P.W. (2003) The behavior of U- and Th-series nuclides in groundwater. In: Uranium-Series Geochemistry (eds. B. Bourdon, G.M. Henderson, C.C. Lundstrom and S.P. Turner), Mineralogical Society of America, Wash. D.C., pp. 317-361.

Tricca A., Wasserburg G.J., Porcelli D. and Baskaran M (2001) The transport of U- and Th-series nuclides in a sandy unconfined aquifer. Geochim. Cosmochim. Acta 65, 1187-1210.

Tritton D.J. (1988) Physical Fluid Dynamics (2 ${ }^{\text {nd }}$ Ed.) Clarendon Press, Oxford.

Volpe A. M., Olivares J.A. and Murrell M.T (1991) Determination of radium isotope ratios and abundances in geologic samples by thermal ionization mass spectrometry. Anal. Chem. 63, 913916. 